\title{
Characteristics study of nanostructured CdO prepared by spray pyrolysis
}

\author{
Raid A.Ismail ${ }^{1}$, Sa'ad Ghafori ${ }^{2}$, Rafal S. Sichat ${ }^{2}$ \\ ${ }^{1}$ Department of Applied Science, University of Technology, Baghdad, Iraq \\ ${ }^{2}$ College of Science for Women, University of Baghdad, Iraq \\ E-mail address: raidismail@yahoo.com
}

Keywords: cadmium oxide, concentration, spray pyrolysis, optical properties

\begin{abstract}
In this paper, nanostructured cadmium oxide films were prepared by chemical spray pyrolysis technique.The structural, morphological and optical characteristics of synthesized films are investigated as function of concentration. AFM results revealed that the root mean square of surface roughness is increased with cadmium concentration. XRD investigation confirmed that the films are polycrystalline with cubic structure. SEM study displayed that the synthesized films have particle size in the range of $25-100 \mathrm{~nm}$ depending on cadmium ion concentration. The optical properties revealed the films have maximum average optical transmittance of $78 \%$ for film sprayed with $0.1 \mathrm{M}$. The optical band gap of the $\mathrm{CdO}$ film prepared with $0.25 \mathrm{M}$ was $2.65 \mathrm{eV}$. The optical band gap increased as the film molarity
\end{abstract}

\section{INTRODUCTION}

Cadmium oxide films are very promising semiconductor due to its high optical transparency and high electrical conductivity. $\mathrm{CdO}$ is n-type with wide direct optical band gap of $2.4 \mathrm{eV}$ at room temperature. It was used widely in many application such as transparent electrodes, solar cells , photo transistors ,gas sensors, photodetectors [1-3 ]. Many methods was employed to synthesis $\mathrm{CdO}$ thin films e.g sputtering, thermal evaporation, laser deposition ,rapid thermal oxidation of cadmium, sol-gel, chemical bath deposition and spray pyrolysis [4-8]. The spray pyrolysis technique was used extensively for TCOs film preparation due to its simplicity and large area formation.It is reported that the properties of sprayed films are strongly depended on preparation conditions for instance substrate temperature, spray rate, distance between nozzle and substrate and cooling rate[9]. Here, we report on synthesis of nanostructured $\mathrm{CdO}$ films by spray pyrolysis technique. The dependence of film characteristics on the molarity was also studied.

\section{EXPERIMENTAL}

For deposition of $\mathrm{CdO}$ films, a aqueous solution of cadmium acetate $\left(\mathrm{CH}_{3} \mathrm{COO}\right)_{2} \mathrm{Cd} .2 \mathrm{H}_{2} \mathrm{O}$ was sprayed with cadmium ion concentration ranging from $0.1 \mathrm{M}$ to $0.25 \mathrm{M}$ on cleaned hot glass substrates using home- made spray pyrolysis system. The distance between the glass nozzle and substrate was $19 \mathrm{~cm}$. The substrate temperature was kept around $400^{\circ} \mathrm{C}$ and the spray rate was around $1.5 \mathrm{cc} / \mathrm{min}$. The carrier gas used in this study was compressed air . X-ray diffractometer (XRD-6000, Shimadzu) was used to study the structural properties of prepared films. Scanning electron microscope SEM ( T-scan Vega III Czch) and atomic force microscope AFM (AA 3000 Scanning Probe Microscope ) were employed to investigate the surface morphology of grown films. The optical properties of films was studied with aid of UV-Vis spectrophotometer (Union space international LTD UV-1601) in spectral range of 300-1100nm. 


\section{RESULTS AND DISCUSSION}

Fig. 1 shows the XRD patterns of nanostructured $\mathrm{CdO}$ films prepared with different cadmium ion concentrations. All the grown films are polycrystalline in nature with cubic structure, the diffraction peaks noticed at $33^{\circ}, 38.6^{\circ}, 55.7^{\circ}, 66.5^{\circ}$ and $69^{\circ}$ which corresponded to (111), (200), (202), (311) and (222) planes, respectively are indexed to bulk CdO according to JCPDS Card No. 65-2908.The XRD pattern of $\mathrm{CdO}$ film prepared at $0.1 \mathrm{M}$ revealed that the (200) plane grew predominantly than the other diffracted planes and its intensity decreases as cadmium ion concentration increase. The intensity of (111) plane increased with concentration due to the fact that the surface energy density of (111) plane is very low compared to other planes [ 8 ].The particle size D of the film was estimated from Scherrer's formula.

$$
D \frac{0.9 \lambda}{\beta \cos \theta}
$$

Where $\lambda$ is $x$-ray wavelength, $\beta$ is angular line width of half maximum intensity, and $\theta$ is Bragg's angle. The values of average grain size was in the range of $18-25 \mathrm{~nm}$ and it is noticed that it is slightly changed with concentration.Fig. 2 displays the transmittance of $\mathrm{CdO}$ films prepared at various concentrations of cadmium, it is clear that increased the concentration resulted in decreasing the film transmittance .The average optical transmittance of $\mathrm{CdO}$ films were $68-78 \%$ and the maximum transmittance was observed for film synthesized at $0.1 \mathrm{M}$. The optical energy gap of $\mathrm{CdO}$ films was calculated by plotting $(\alpha h v)^{2}$ versus photon energy $h v$ and the extrapolation of linear part to the photon energy axis give the value energy gap as shown in Fig.3.Table 1 lists the values of optical energy gap as function of cadmium concentration. From table 1 it is obvious that the optical energy gap increased with increasing of concentration due to decreasing of particle size and this point will supported with the results of SEM and AFM. The maximum value of energy gap obtained for $\mathrm{CdO}$ films was $2.65 \mathrm{eV}$ which is larger than that for bulk $\mathrm{CdO}(2.4 \mathrm{eV})$. .Increasing the energy gap of film can be ascribed to quantum size effect. 


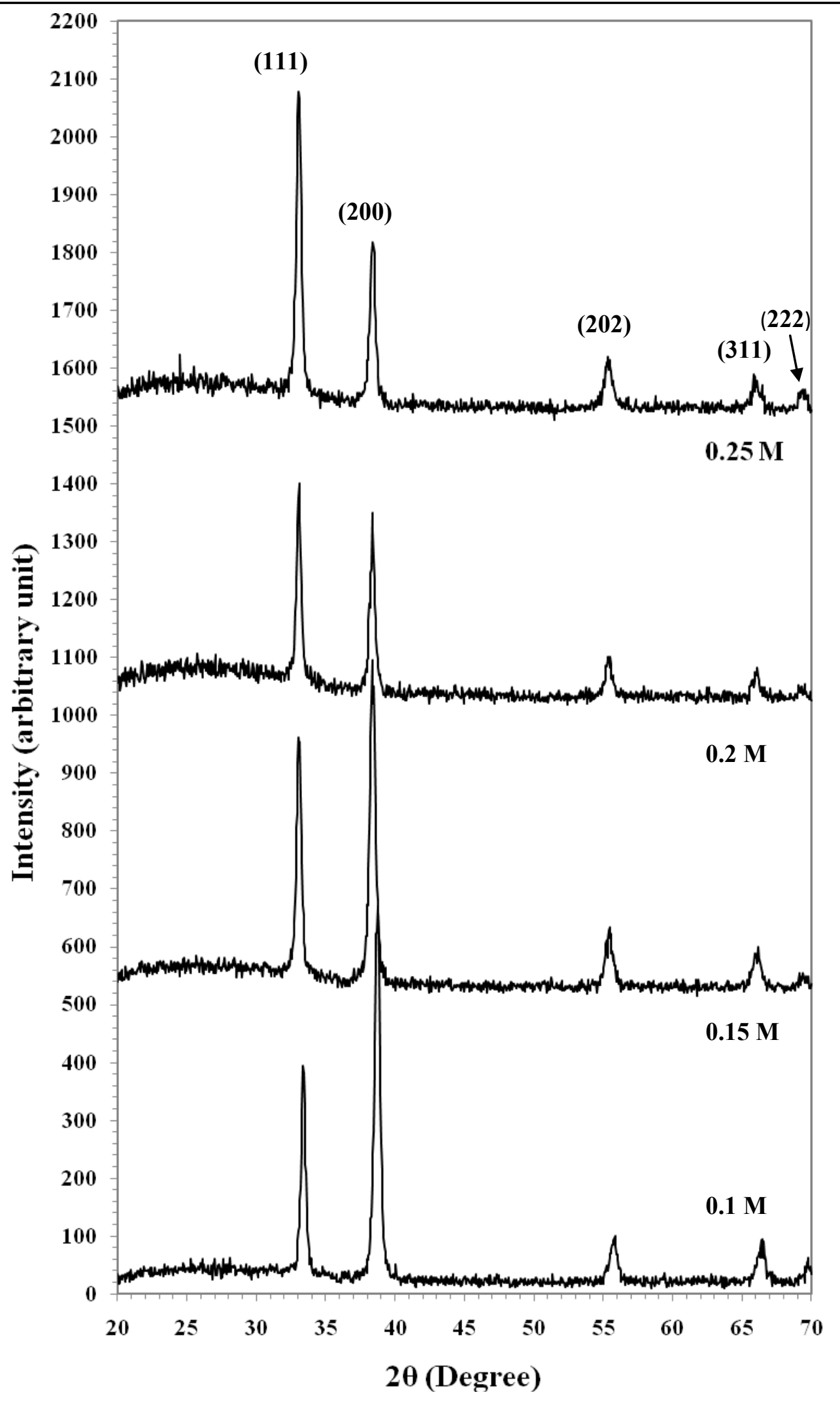

Fig.1. XRD patterns of sprayed CdO films prepared at different concentrations 


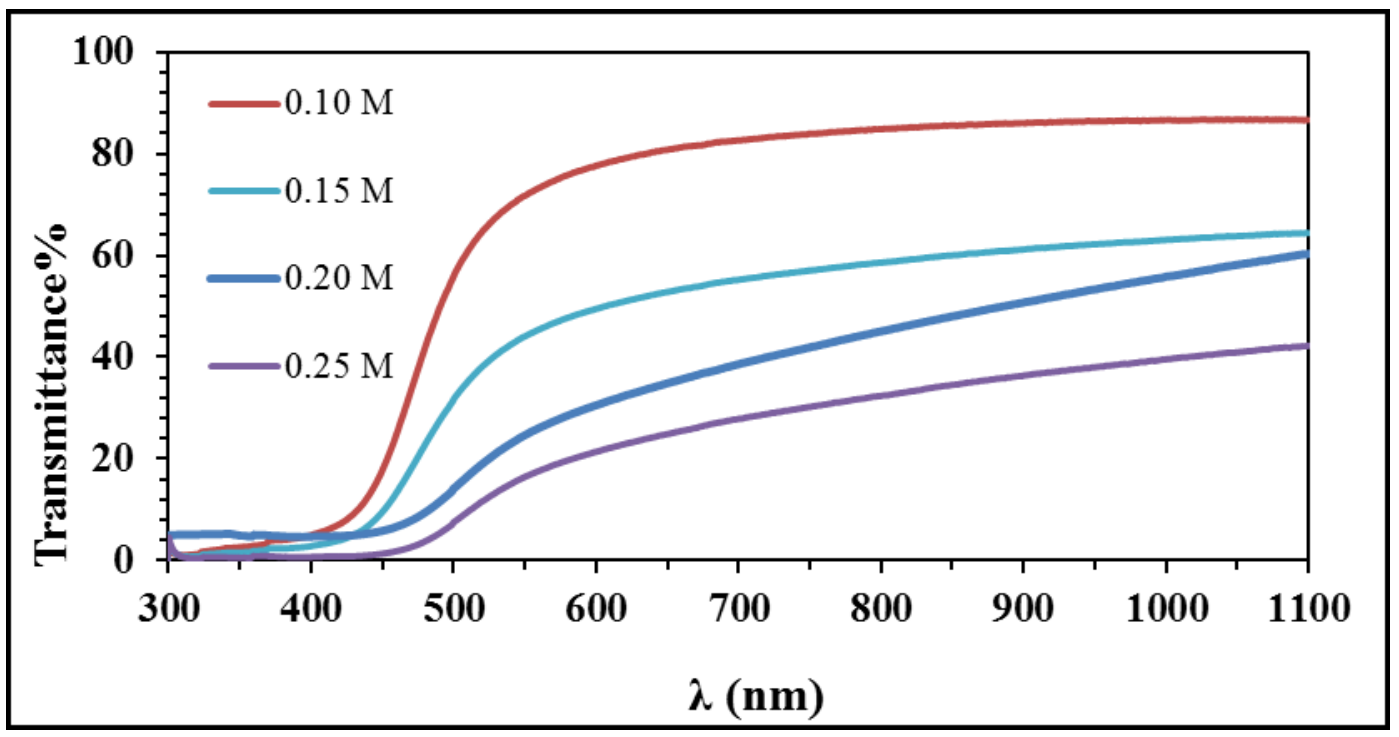

Fig.2. Transmittance of $\mathrm{CdO}$ films synthesised at various concentrations

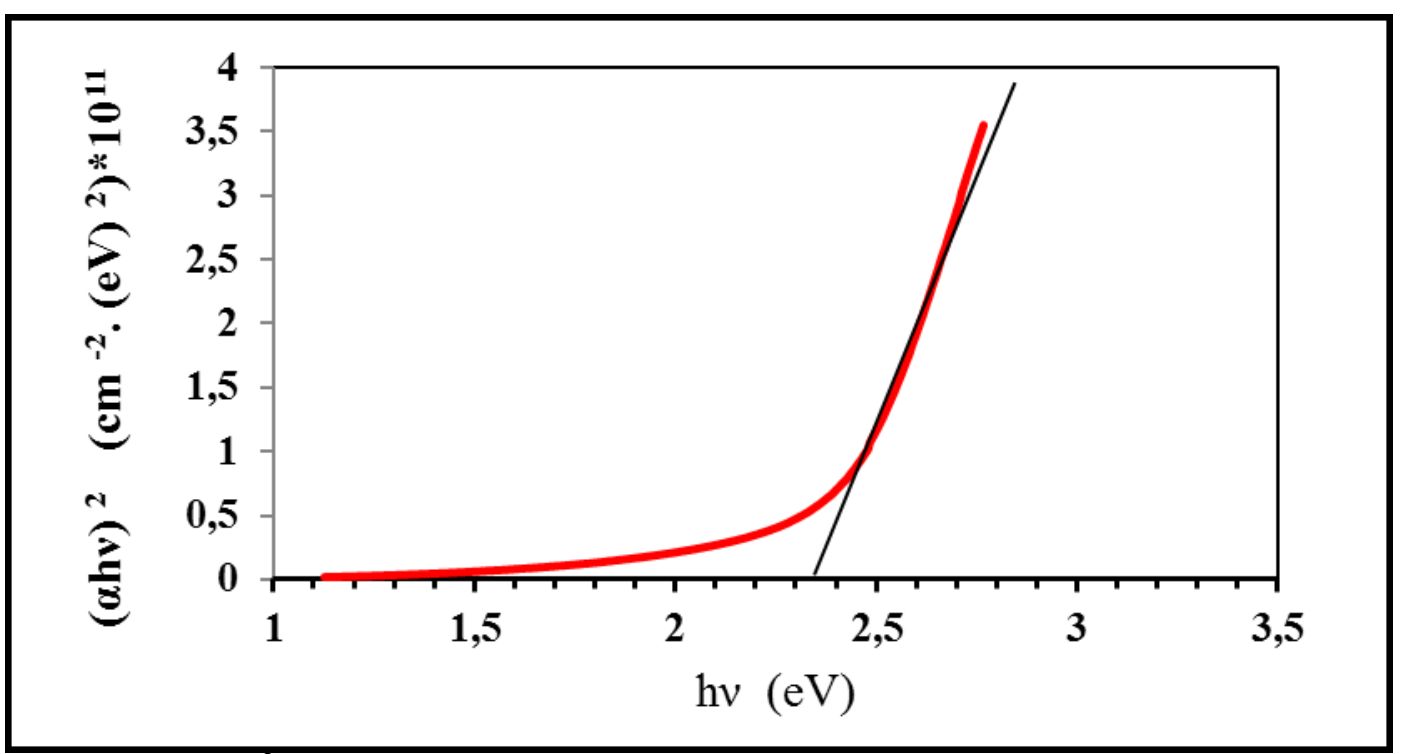

Fig.3. $(\alpha h v)^{2}$ versus photon energy plot for $\mathrm{CdO}$ film prepared at $0.1 \mathrm{M}$

Fig. 4 shows the 2D and 3D AFM images of $\mathrm{CdO}$ films prepared at various concentrations. AFM images confirmed that the $\mathrm{CdO}$ films prepared with low concentration have particles with spherical shape and in nanosized .These particles are aligned vertically. 

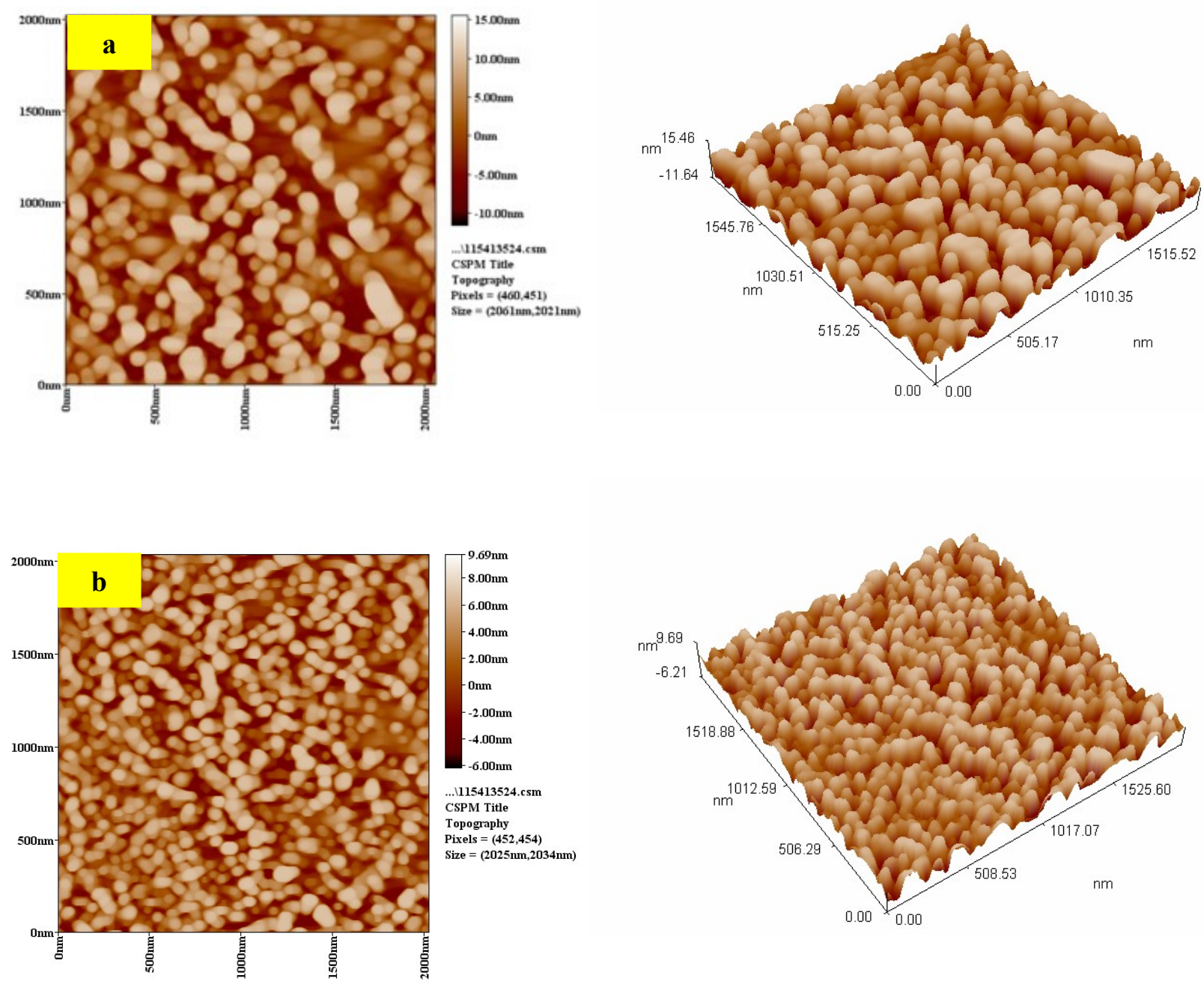

Fig.4. 2D and 3D AFM images of nanostructured CdO films prepared at (a) $0.1 \mathrm{M}$ and (b) $0.15 \mathrm{M}$ (c)0.2 $\mathrm{M}$ and (d) $0.25 \mathrm{M}$ 

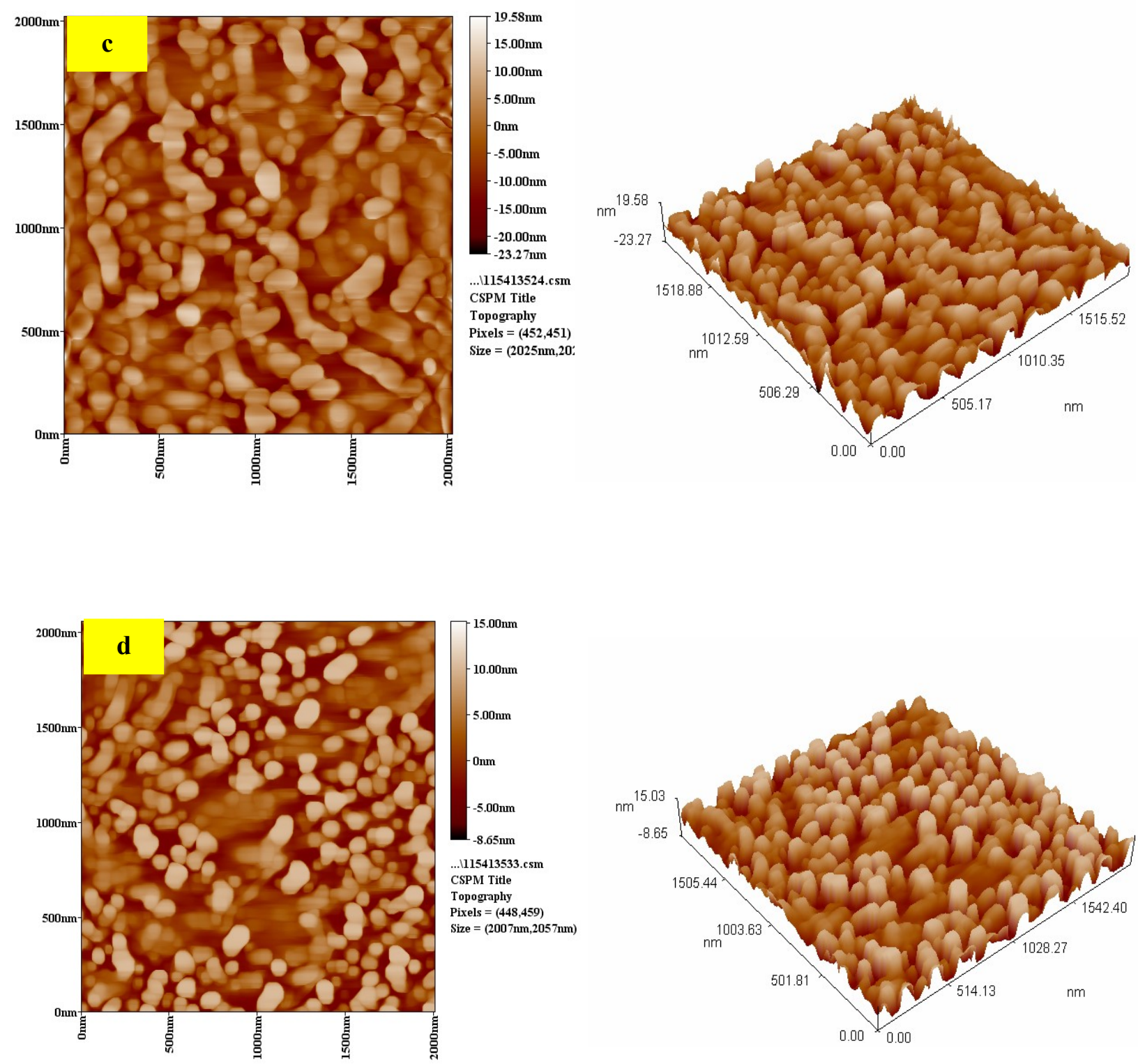

\section{Continued}

The average particles size is noticed to decrease with increasing the concentration. On the other hand, the root mean square of surface roughness increases as concentration increased as shown in table 2. Fig.5 shows the SEM images of CdO films prepared at $0.1 \mathrm{M}$ and $0.15 \mathrm{M}$. It is clear that the particles have elongated particles and semi-spherical shape with different sizes .The $\mathrm{CdO}$ film prepared with $0.1 \mathrm{M}$ gave an average particles size of $87 \mathrm{~nm}$, while the film prepared with $0.15 \mathrm{M}$ have particles with $45 \mathrm{~nm}$ average size. Particles agglomeration was noticed for all prepared $\mathrm{CdO}$ films. The SEM image of film prepared with $0.25 \mathrm{M}$ (not shown) revealed the particle size around $25 \mathrm{~nm}$. The disagreement in particle size found from XRD and SEM can be attributed to the agglomeration of particles as well as the increasing the value of FWHM in XRD may be comes from the stress not due to the decreasing of particles size . 

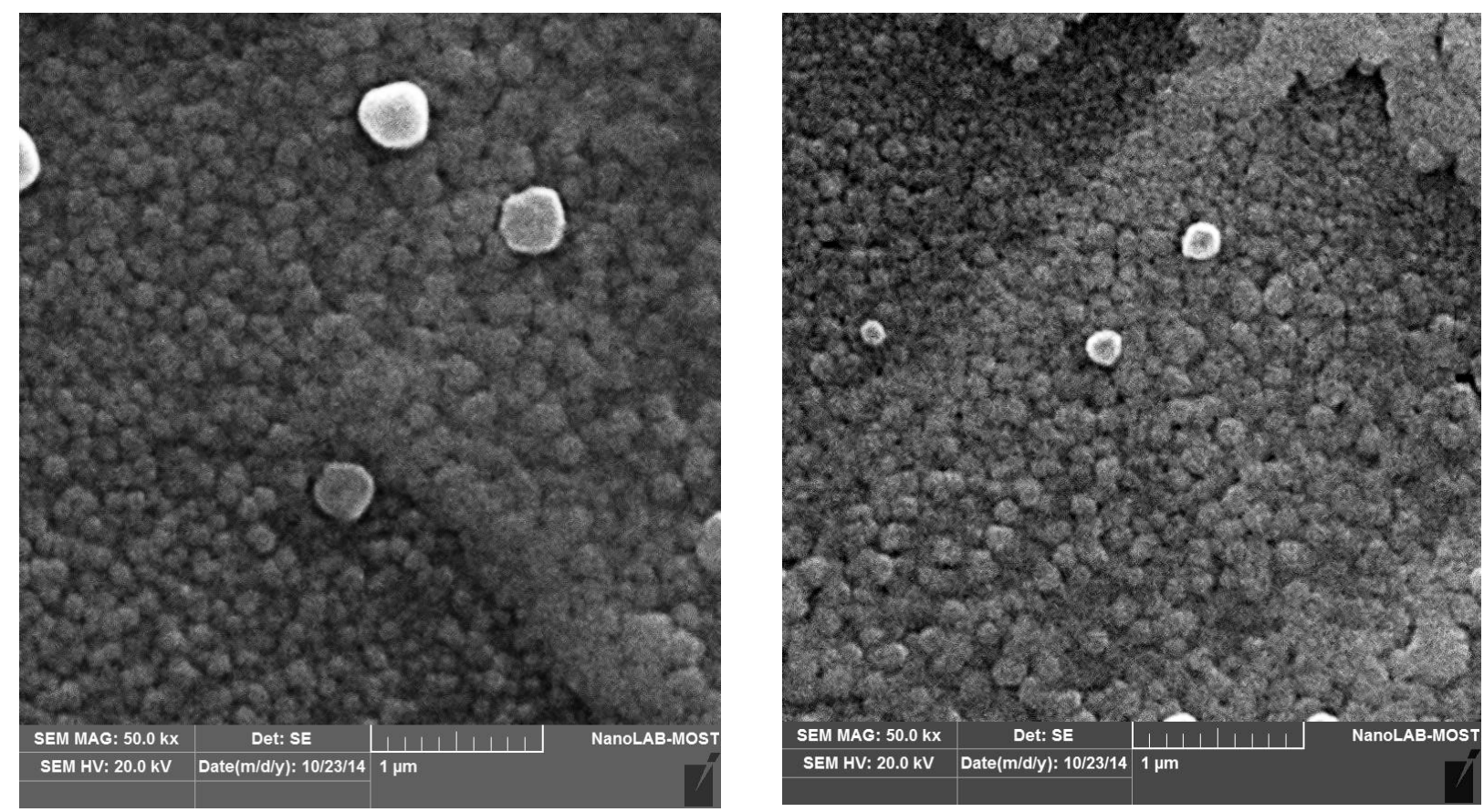

Fig.5 SEM images of nanostructured CdO films prepared at (left) $0.1 \mathrm{M}$ and (right) $0.15 \mathrm{M}$

Table 1. Optical energy gap for $\mathrm{CdO}$ films prepared at various cadmium concentrations

\begin{tabular}{|c|c|}
\hline $\begin{array}{c}\text { Cadmium } \\
\text { Concentration(M) }\end{array}$ & Energy gap (eV) \\
\hline 0.1 & 2.30 \\
\hline 0.15 & 2.38 \\
\hline 0.2 & 2.52 \\
\hline 0.25 & 2.65 \\
\hline
\end{tabular}

Table 2. Surface roughness and grain size as function of cadmium concentrations

\begin{tabular}{|c|c|c|}
\hline $\begin{array}{l}\text { Cadmium } \\
\text { Concentration(M) }\end{array}$ & $\begin{array}{l}\text { Surface roughness } \\
\text { (nm) }\end{array}$ & $\begin{array}{l}\text { Average grain } \\
\text { size(nm) }\end{array}$ \\
\hline 0.1 & 2.34 & 100 \\
\hline 0.15 & 4.1 & 89 \\
\hline 0.2 & 4.47 & 75 \\
\hline 0.25 & 5.28 & 71 \\
\hline
\end{tabular}

\section{CONCLUSION}

Nanostructured CdO films was synthesised by using spray pyrolysis technique. The effect of cadmium ion concentration on the structural, morphological, structural, and optical properties of grown films has been demonstrated. XRD confirmed that the grown films have cubic structure. The prepared films have different particle s sizes in the range of $25-100 \mathrm{~nm}$ with semi-spherical shape. The values of optical energy gap for $\mathrm{CdO}$ films prepared at high concentration were larger than that for bulk $\mathrm{CdO}$ at room tepmperature. 


\section{References}

[1] Dakhel A., Bull. Mater. Sci. 37( 2014) 1509.

[2] Calnan S. , Tiwari A. N. ,Thin Solid Films 518 (2010) 1839.

[3] Ismail R.A., Al-Samarai A.E., Mohmed S.J., Ahmed H.H, Solid-State Electron. 82(2013) 115.

[4] Ismail R.A., Abdulrazaq Omar A. , Solar Energy Materials \& Solar Cells 91 (2007) 903

[5] Lu H.B., Liao L., Li H., ET AL.,Mater. Lett., 62(2008)3928.

[6] Fan D.H., Crystal Growth 311(2009) 2300.

[7] Dhawale D.S., More A.M., Latthe S.S., Rajpure K.Y., Lokhande C.D., Appl. Surf. Sci. 254(2008)3269.

[8] Dong Ju Seo, Journal of the Korean Physical Society 45( 2004)1575.

[9] Ma Y. Y. , Bube R. H. , J. Electrochem. Soc. 124 (1977)1430. 